\title{
Effects Of Mobile Phones Radiation On The EEG And EMG Of Human Users.
}

\author{
Fathy El-Komey \\ The National Center for Social and Criminological Research,
}

\begin{abstract}
This study focuses on the effect of mobile phone radiation emissions on the human electroencephalograph (EEG) and electromyogram activity (EMG). EEG and EMG recordings from 50 (male and female) awake subjects were taken during exposure to radiation emissions from a mobile phone. Our results demonstrated that stimulation effects became apparent on EEG at first, and changes varied strongly at the end of the experiment to depression. EEG and EMG showed interesting changes. The results suggested that cellular phones may reversibly influence the human brain, as their use induced abnormal slow waves in EEG of awake persons.
\end{abstract}

\section{Introduction}

At present, the heads of many current phone users have been exposed to a sequence of microwave fields modulated in substantially different ways (Adey, 1997). Initial transmission systems utilized 400 $\mathrm{MHz}$ frequencies, but current systems generally transmit at 900 and $1800 \mathrm{MHz}$ (Kuster et al., 1997). The Global System for Mobile Communication (GSM) system employed throughout Europe, Egypt and in much of the rest of the world is encoded at $217 \mathrm{pulses} / \mathrm{sec}$.

The following is a brief summary of scientific research on the effects of radiofrequency electromagnetic radiation (RFR) exposure on human.

Kuster et al. (1997) reported that mobile phones when hand-held and operated close to the head, background levels are sharply distorted, with 40 percent of radiated phone energy absorbed in the hand and the head. Frey (1998) and Oftedal et al. (2000) reported that mobile phones cause headaches. Chia et al. (2000) reported that headaches were significantly more common among users of hand-held mobile phones than among non-users $(65 \%$ vs. $54 \%$ ).

Hardell et al.(2002 a\&b,2003 a\&b) published four separate analyses of a follow-up study of 1617 brain tumor patients. This study included both benign and malignant brain tumors, and both mobile phone and cordless phone-users. Benign brain tumors made up to $55 \%$ of the total, and $35 \%$ were users of cordless rather than cellular phones.

Stang et al. (2001) reported that the use of radio sets, mobile phones, or similar devices at the workplaces for several hours per day, was associated with uveal (intraocular) melanoma. Of 118 individuals with intraocular melanoma, $6 \quad(5.1 \%)$ reported that they were "probable or certain" to have "ever been exposed" to mobile phones at work. According to the authors, this occupational mobile phone use was 4 times higher than expected. Mobile phone use outside of work was not assessed, and other risk factors (for example, UV exposure and light skin color) were not assessed. In the only other comparable study found in the literature, Johansen et al. (2001) found less melanoma and ocular cancer than expected in mobile phone users. Muscat et al.(2000) published a report on malignant brain tumors and the use of hand-held mobile phones, and found that tumors were more frequent on the side opposite to that used for where the phone, than on the same side where the phone was reported to be used.

Reiser (1995) reported a change in EEG tracings on exposure to $900 \mathrm{MHz}$ radiation, but others have stated that similar changes can be seen when the level of 
awareness is altered. Huber (2002) found changes in the alpha range during pulsemodulated exposure, but not with continuous wave exposure.

\section{EEGs on exposure to radiofrequencies while awake and during sleep:}

Borbely et al. (1999) found a slight reduction in the duration of waking, after sleep onset had occurred. Huber(2000) also reported that exposure to electromagnetic filed (EMF) for 30 minutes before sleep altered EEG patterns during subsequent sleep. However, no difference in sleep onset latency or sleep stages, or in waking after sleep onset was found.

Freude et al. (1998 \& 2000) reported some modulation of the EEG during performance of some of the tasks, but their results were inconsistent. Krause (2000) reported EEG changes in healthy volunteers exposed to an EM field of $902 \mathrm{MHz}$ during performance of an auditory task, or a visual memory task. Jech (2001), also, found EEG changes in response to visual tasks. Freude et al. (2000) exposed human volunteers to RF radiation from a GSM phone and found small changes in EEG that "did not indicate any influence on human performance, wellbeing or health". Edelstyn and Oldershaw (2002) and Lee et al.(2003) reported that exposure of human volunteers to $900 \mathrm{MHz}$ $\mathrm{RF}$ radiation from mobile phones improved their performance on tests for "attention".

In a review of the reports on effects of mobile phones on brain function and behavior, Hossmann and Hermann (2002) concluded that most of the reported effects are small as long as the radiation intensity remains in the nonthermal range.However, Borbely et al.(1999) ; Huber et al.(2003) reported that exposure to a mobile phone signal could cause slight changes in sleep patterns and sleeping EEG, while Kramarenko and Tan (2003) reported subtle changes in the brain function (EEG) of mobile phone users.

Zwamborn et al. (2003) found that laboratory exposure of human volunteers to base station RF radiation caused decreased feelings of "well-being" and improvement on some cognitive function tests (e.g., reaction time and memory tests). The effect on "well-being" was found only for the UMTS (Universal Mobile Telecommunications Service) type of signal used by G3 (third generation) mobile phone systems; it was not found for GSM mobile phone signals (the system that now dominates Europe). The effects on cognitive function occurred in 8 of 30 tests for both UMTSlike and GSM signals.

In a review of the effects of RF radiation on behavior, D'Andrea et al. (2003) found that exposure to RF radiation can lead to changes in the behavior of humans and laboratory animals that can range from the perceptions of warmth and sound to lethal elevation of body temperature.

In a review of the auditory response to pulsed radiofrequency energy (also called "microwave hearing"), Elder and Chou (2003) concluded that: "The hearing of RF [radiation] induced sounds at exposure levels many orders of magnitude greater than the hearing threshold is considered to be a biological effect without an accompanying health effect. This conclusion is supported by a comparison of pressure induced in the body by RF pulses to pressure associated with hazardous acoustic energy and clinical ultrasound procedures."

Krause et al. (2000) had reported that human volunteers who were exposed to 902 $\mathrm{MHz}$ RF from a GSM phone showed changes in brain activity (EEG) and performance on memory tasks, however, these effects could not be confirmed in a doubleblind replication study(Krause et al., 2004). Hamblin et al. (2004) found that 1 hour of exposure of human volunteers to mobile phone RF radiation resulted in decreased reaction times. On the other hand, Tahvanainen et al. (2004) reported that $35 \mathrm{~min}$ of exposure of human volunteers to mobile phone RF radiation (900 or $1800 \mathrm{MHz}$ ) had no effect on blood pressure or heart rate. Burch et al. (2002) reported that mobile phone use of greater than $25 \mathrm{~min}$ per day was associated with a drop in melatonin excretion in electrical workers.

\section{Evidence for RF exposure might be genotoxic:}

d'Ambrosio et al. (2002) reported that phase-modulated $1748 \mathrm{MHz}$ RF radiation 
was genotoxic to human cells at $5 \mathrm{~W} / \mathrm{kg}$ (micronucleus assay), but, a continuous wave signal was not. On the other hand, Tice et al. (2002) reported that while RF radiation did not cause DNA strand breaks, it might enhance micronucleus formation. The authors speculate that the effects might be heat-induced.

Trosic et al. (2002) exposed rats to $2450 \mathrm{MHz} \mathrm{RF}$ radiation at 5-10 $\mathrm{mW} / \mathrm{cm}-\mathrm{sq}$ for $2 \mathrm{hr} /$ day for up to 30 days; (SARs were estimated to be $1-2 \mathrm{~W} / \mathrm{kg}$ ). An increase in micronucleus incidence was seen after 8 days of exposure, but not after longer or shorter intervals.

Mashevich et al. (2003) reported that exposure of human white blood cells to thermal levels of RF radiation caused genomic instability, but this effect was not caused by another method of heating.

Clinical neurophysiology is a diagnostic specialty concerned with recording and interpreting electrical signals from the nervous system. There are three main areas:1- Electroencephalography (EEG).2Nerve conduction studies and electromyography (EMG). 3-Responses evoked by sensory stimulation (Career, 2003).

\section{Aim of the work}

Our work focused on effects of the frequency electromagnetic fields of cellular phones [mobile phone signal (GSM) 900$1800 \mathrm{MHz}$ ] on humans. In this work, attention will be confined to GSM by Vodafone company and Mobinel company which are those used in Egypt "Air wave" or "microwave systems" of telecommunication (GSM).

This study focuses on two specific issues: 1) evaluation of the changes in the EEG and EMG of healthy normal volunteers of both sexes exposed to 900 and $1800 \mathrm{MHz}$ from mobile phones for 12 months. 2)identification of the specific summary of scientific research on the effects of RFR exposure on humans.

\section{Human Experimental Studies - EEG:}

The electroencephalogram (EEG) records the scalp electrical activity emitted by nerve cells from the cortex of the brain.
The EEG has different "bands", defined by the frequency of the waves; the theta bands are $4-8 \mathrm{~Hz}$, the alpha from 8 to $12 \mathrm{~Hz}$, the beta from $14-30 \mathrm{~Hz}$ and the gamma from $30-80 \mathrm{~Hz}$. The alpha bands are best seen in the parieto-occipital area, and the beta bands are usually more prominent in the frontal and central regions. The alpha rhythm contains waves of $8-12 \mathrm{~Hz}$ and is very responsive to volitional mental activity, increasing with excitement and decreasing with tranquility. These rhythms occur mainly in the posterior head and are the predominant brain activity in the normal brain. The beta rhythm occurs in the prefrontal regions and has been associated with increased cognitive activity. Higher levels of beta activity have also been associated with anxiety and delirium .These bands, when simultaneously recorded, differ from each other and reflect different cognitive processes. The alpha rhythm is best seen when the subject is awake and relaxed, with eyes closed (Lopes 1982; David 1997 and Ernst and Lopes, 1999).

\section{Volunteers and methods:}

50 healthy adult volunteers of either sex (male or females) were used. Their age ranged from 18-26 years. Volunteers with an associated medical problem were excluded.

The changes of the EEG and EMG and the subjective symptoms mentioned by the volunteers before and after using mobile phones for 12 months, were recorded. EEG recordings from ten awake subjects were taken during exposure to GSM from a mobile phone positioned on the head and the EMG was recorded from the legs while the mobile phone was put in the pocket of the trousers or belt in male subjects, or in a hand bag near the thigh in female subjects.

The 50 volunteers required to run the EEG and EMG were: age, 18-26 years; height, $153-175 \mathrm{~cm}$; weight, $49-68 \mathrm{~kg}$ (Table 1). They were required to run on a treadmill and EMG data were acquired from four different muscle groups of the leg:

1- The muscle of thigh "four thigh bones" (Biges femoral). 
2- The muscle of femoral thigh ( Biceps long $\mathrm{H}$ ).

3- The long tibila (Tibialis nticus).

4- The big antomatism (Gluteus max.).

\section{Electromyography (EMG):}

Electromyography (EMG) is the technique for measuring and recording electrical potentials that are associated with contractions of muscle fibers. The EMG is often used in the clinic to study muscular disorders. The EMG was recorded from the skin surface according to the methods of Thompson et al. (1966), Merletti and Lo Conte(1995), and John (2000). The electrodes were placed on the skin over an active muscle record the algebraic sum of a large number of depolarizations that occur when a group of motor units are activated (Lippold, 1967 ; John, 2000).

\section{Electrode Placement for EMG Recording:}

The general principles for electrode application were the same as for other physiological measures. That is, the skin must be cleaned with alcohol or some mildly abrasive material to remove dead skin, dirt, and oils. Then, the electrode gel was rubbed into the area and the excess was removed, the recording electrode containing a new supply of gel was placed into the desired position. Pregelled electrodes are also commercially available for convenience purposes. The EMG is most commonly recorded with a bipolar electrode arrangement, with both electrodes located over the muscle of interest. The resistance between the electrodes should not exceed 10,000 Ohms and should be lower if possible (e.g., 5,000 Ohms). The subject, the EMG recorder, and the electrical equipment close to, it should all be grounded to protect the subject and to prevent 60-cycle interference in the recording. Once exposed to electrode gel, the electrodes will start to deteriorate. They must be washed in warm water and soap after each use and then rinsed thoroughly in clear water to remove all traces of electrolytes. Bipolar recordings are more sensitive to variations in the gradients of muscle activity between the two electrodes.

\section{Specific Electrode Placements:}

Placement of electrodes over different muscle areas have been outlined by Basmajian and Blumenstein (1983) as shown in Figure (18).

\section{Recording the EMG:}

EMG activity was transmitted from New Ropak's model 2 system two channels (figure 17). The system consists of a highperformance EMG sensor, signal amplification, conditioning circuit and a transmitter/ receiver. The EMG data were transmitted to a compatible computer for storage and data processing. Then the mean power frequency of the EMG signal will be calculated and used to indicate local muscle effect. The EMG signals were amplified, with gain of 2, 000, and sampled with an $\mathrm{A} / \mathrm{D}$ card with the synchronizing signal at 1,000 samples per second, after filtering with an appropriate antialiasing filter. In order to be able to use the data collected from muscle, the signal must be 'clean', i.e. free from noise, artifacts and distortion (Winter, 1990).

As mentioned previously, the technique of integration helps considerably in the analysis of EMG activity. Essentially, the integrator provides a measure of total EMG output over a given period of time according to Bonato et al. ( 1998) for analysis of EMG activity.

\section{EEG Recordings:}

EEGs were recorded in a mini-8 EEG machine (Alvar, REEGA, Paris, France) using EEG electrodes according to the International 10-20 System. The time constant was 0.3 seconds with a paper speed of $15 \mathrm{~mm} / \mathrm{sec}$ and the sensitivity was 10 $\mu \mathrm{V} / \mathrm{mm}$. Data were inspected on-line and stored on paper for subsequent analysis.

Two EEGs were recorded for each volunteer. The first was a baseline measurement performed over 30 minutes before using the mobile. Then the mobile phone was used for 20 minutes/day through two weeks (state 1). Afterwards EEG was recorded after 4,8 and 12 months of continuous use of the mobile every day (20 minutes/day, state 2 ). 


\section{EEG Analysis:}

The analysis of each EEG included both qualitative and quantitative parameters. Qualitative parameters assessed were physiologic patterns for the given postconceptional age using a standard textbook of volunteers electroencephalography, sleep states, pathologic figures (positive rolandic sharp waves or seizures), and unusual pattern for the given postconceptional age (e.g., fast rhythms). Quantitative parameters were analyzed every 40-second epoch, and EEG activity was divided into bursts. Bursts included any epoch with clear EEG activity. The following parameters were calculated: number of bursts by epoch; mean duration of bursts and, maximum burst and duration in each recording, and percentage of bursts during the whole recording.

\section{Statistical Analysis:}

Qualitative data were analyzed by Student $\mathrm{s}$ t test. $P$ value $\leq 0.05$ was considered significant. Results are reported as means \pm standard deviation.

\section{Results and Discussion}

State 1 biphasic effects in the first stage, showing manifestations of stimulation followed by depression, higher stage also produced depression. Baseline EEG energy of males was greater than that of females, while exposure to GSM decreased EEG energy of males and increased that of females. These results indicate that mobile phone exposure has functional consequences for human subjects, and these effects appear to be sex-dependent.

A state of excitement or distraction and CNS stimulation showed opposite effects. At the end of experiment visual analysis revealed minimal changes in the first four months (decreased amount and frequency of alpha activity ). After six months, the voltage of slow activity was generally increased, the frequency of alpha rhythm was decreased, and beta activity was increased. Paroxysmal bursts and focal slowing with super imposed beta or irregular (9-10 $/ 0 \quad \mathrm{HZ})$ activity with increased theta and delta activity were recorded at the end of the experiment as shown in Figures (1-16).

The reduction of the alpha activity of the EEG and the enhanced amplitude of the low frequency waves suggest the occurrence of depression.

Facial or limb myoclonus associated with polyspike -and- wave discharges were observed in normal subjects. Spontaneous epileptic discharges occurred in 50\% of volunteers (25 from 50 ), with spike - and wave discharges. EEG showed slowing with decreased frequencies of alpha or background rhythms. EEG epileptic form discharges or ictal patterns were also observed. Paroxysmal activity and epileptic form discharges can occur during the use of the mobile. Seizures usually occurred: GSM can produce several abnormal patterns, including increased epileptiform discharges and synchronous rhythmic activity. Focal EEG abnormalities were recorded in $62 \%$ ( 31 from 50) ["abnormal rhythms" in 52\% (26 from 50), and spikes in $17 \%$ ( 9 from 50)].

GMS produced EEG characterized by spikes and at 12 months, spike - and slow - wave complex alternating with periods of bursts - suppression together with seizures. These results agree with those of Krause et al. (2000) .

The present results showed that GMS cause or increase focal sharp waves, spikes, spike and wave complexes, and paroxysmal delta activity and increase EEG dysynchronization, a state of draw senses and CNS depressant effect, and also caused synchronization of EEG and increase in alpha activity.

These results agree with those of Krause et al. (2000) who reported that 30 min head exposure increased relative cerebral blood flow in the dorsolateral prefrontal cortex on the exposed side. These pulsed GSM fields also enhanced EEG power in the alpha $(8-13 \mathrm{~Hz})$ range prior and in the spindle frequency range during recording. (Adey, 1997; Huber et al., 2002). Huber (2002) found changes in the alpha range during pulse-modulated exposure, but not with continuous wave exposure. Exposure to mobile phone RF radiation led to decreased reaction times in human 
volunteers. Hamblin et al. (2004) and Zwamborn et al. (2003) reported that laboratory exposure of human volunteers to base station RF radiation caused decreased feelings of "well-being" and improvement on some cognitive function tests (e.g., reaction time and memory tests).

The results also showed an initial increase in excitability of the brain after mobile use (GMS exposure) followed by inhibition (cortical synchronization and slow wave) after prolonged exposure to GMS. After chronic exposure to GMS of the mobile, desynchronization was seen in the EEG , whereas synchronization was observed in the controls. Periods of alternating EEG desynchronization and synchronization in volunteers according to the duration of daily use and, thus, exposure to GMS were reported. These results confirm those of Smith and Best (1989), Freg (1998), Muscal et al. (2000), Stang (2001), Hamblin and Wood (2002), Burch et al.( 2002), Hardell et al. (2002) and Salford (2003). The results also agree with Hocking (1998) who reported headaches with pain radiating to the jaw, neck, shoulders or arm in few of the 40 respondents studied. All studied cases could distinguish the headaches as different in quality from typical headaches. Some cases reported transient effects on vision such as blurring, nausea or dizziness, which made thinking difficult. One case of Dr. Hocking experiment had long-standing tinnitus, but after prolonged mobile phone calls developed deafness and vertigo lasting five hours. Mild et al. (1998) reported on a joint Swedish-Norwegian epidemiological study of cases using both GSM digital and analogue mobile phones. A statistically significant association between calling time/ number of calls per day and the prevalence of warmth behind/around the ear, headaches and fatigue was reported which agree with our results. Also, the present results are in complete agreement with Costa et al. (2003) and Marino et al.( 2003) who concluded that, in normal use, the fields from a standard cellular telephone can alter brain function as a consequence of absorption of energy by the brain.
In our study, the EMG was compared before and after the use of the mobile phone. Exposure to GMS (900- 1800) from mobile use, is capable to repeat stress, thus inducing inhibition as shown in Figures (19-22). Through the comparison of premeasures and postmeasures and performing the statistical analysis, the study consequences appeared as follows as regards the active muscle:

1- The muscle of thigh "four thigh bones.

2- The muscle of femoral thigh.

3- The long tibila .

4- The big antomatism.

Table (2) shows significant increase in the time of the one constriction frequency for right and left legs muscles ( $\mathrm{P}$ $<0.05)$ compared to that before use mobile phone. The increased duration caused: Increased variability of MF diameter, MF hypertrophy, synchronous firing of 2 MUs and slow AP propagation in terminal axon branches in myopathic processes but in neuropathic processes caused: Re-innervations of more MFs for MU, selective loss of small type I MUs, synchronous firing of 2 MUs, slow AP propagation in terminal axon branches and dispersion of endplate zone according to Nandedkar and Barkhaus (2001\&2002) and Barkhaus and Nandedkar (2003).

Table (3) Shows significant decrease of electric response capacity of the leg muscles $(\mathrm{P}<0.05)$. The duration of potentials was increased and nerve conduction velocity was decreased after using a mobile phone at the end of the experiment. It is hypothesized that GSM exerts its effect by influencing magnesium metabolism, which, in turn, affects the regulation of enzymes , such as ATP, that are important in muscle function .

Table (4) shows increase in the amplitude which increases the time constriction and time of the total activity. Limb myoclonus associated polyspike - and wave discharges after exposure to GSM from mobile (12 months) was observed.The increased amplitude caused: myofiber (MF) hypertrophy (assuming normal membrane function), synchronous firing of 2 MUs and regeneration of MFs in myopathic 
processes, but in neuropathic processes caused : MF hypertrophy (assuming normal membrane function), synchronous firing of 2 MUs, re-innervations of more MFs and selective loss of small type I MUs according to Barkhaus and Nandedkar (1998, $1999 \& 2003$ )

The increase time of one constriction, time constriction frequency and amplitude of the muscle ( a finding in motor neurons disease) leads to the appearance of spontaneous fibrillation potentials greater than normal and much weaker (involuntary movement) than the normal action potential and an increased proportion of polyphasic action potential due to reduction in the number of action potential cramp - like pains in the legs . These are often early symptoms, when degeneration begins in motor supply of legs (Pfurtscheller and Silva,1999).These results are in agreement with Smith and Best (1989), Erren (1997) and Pfurtscheller and Silva (1999) who reported that the changes in electrophysiology due to exposure to GMS can lead to functional changes in the nervous system.

The effect of GMS on EMG can be summarized as follows:

- a decrease of electric response capacity of the muscles.

- an increase in time of the total activity of the muscles.

- an increase in time of the one constriction of the muscles.

- an increase in time of the constriction frequency.

The present data indicate that GMS (900-1800 MHz) can affect the nervous system. Changes in electrophysiology EEG and EMG have been reported in volunteers after cellular telephone use (mobile),i.e. after exposure to GMS. These changes can lead to functional changes in the nervous system.

In order to improve the protection of the public against the possibly harmful effects of the electromagnetic fields from cellular telephones and their base stations, much higher precautionary standards in Egypt is needed, as they already exist in European countries and in the USA. The experiences from these countries show that precautionary health protection and the use of the cellular telephone technology are compatible.

Table (1): General Charterstics of human volunteers

\begin{tabular}{|c|c|c|c|c|c|c|c|c|c|}
\hline \multicolumn{2}{|c|}{ Height $\mathbf{( C m})$} & \multicolumn{2}{c|}{ Weight (Kg) } & \multicolumn{2}{c|}{ Lower limb length(cm) } & \multicolumn{2}{c|}{ Age(years) } & \multicolumn{2}{c|}{ No. of case } \\
\hline Male & Female & Male & Female & Male & Female & Male & Female & Male & Female \\
\hline $155-160$ & $153-155$ & 53 & 49 & 95 & 92 & $18-20$ & $18-20$ & 8 & 12 \\
\hline $160-165$ & $155-157$ & 58 & 50 & 97 & 90 & $20-22$ & $20-22$ & 6 & 8 \\
\hline $165-170$ & $157-159$ & 65 & 55 & 100 & 93 & $22-24$ & $22-24$ & 5 & 7 \\
\hline $170-175$ & $159-161$ & 68 & 59 & 101 & 98 & $24-26$ & $24-26$ & 2 & 2 \\
\hline & & & & & & & 21 & 29 \\
\hline
\end{tabular}

Table (2) : Effect of GMS exposure on EMG (time one constriction and time constriction frequency) of human legs.

\begin{tabular}{|c|c|c|c|c|c|c|c|c|}
\hline \multirow{4}{*}{$\begin{array}{c}\text { Muscle Name } \\
\text { Region }\end{array}$} & \multicolumn{4}{|c|}{ Time one constriction (mV/Sec) } & \multicolumn{4}{|c|}{ Time constriction frequency $(\mathrm{mV} / \mathrm{Sec})$} \\
\hline & \multicolumn{2}{|c|}{ Right leg } & \multicolumn{2}{|c|}{ Left Leg } & \multicolumn{2}{|c|}{ Right leg } & \multicolumn{2}{|c|}{ Left Leg } \\
\hline & Before & After & Before & After & Before & After & Before & After \\
\hline & $X \pm$ S.E. P & $X \pm S . E P$ & $X \pm$ S.E. P & $X \pm$ S.E. P & $X \pm$ S.E. P & $X \pm$ S.E. P & $X \pm$ S.E. P & $X \pm$ S.E.P \\
\hline $\begin{array}{l}\text { Four } \\
\text { (Bige }\end{array}$ & $23 \pm 0.2$ * & $7.34 \pm 0.1^{* *}$ & $2.85 \pm 0.1^{* *}$ & $6.95 \pm 0.2^{* *}$ & $2.51 \pm 0.1^{* *}$ & $7.35 \pm 0.1 \quad-$ & $3.50 \pm 0.1 \quad--$ & $4.64 \pm 0.1$ \\
\hline $\begin{array}{c}\text { Biceps long H } \\
\text { (Femoral thigh) }\end{array}$ & $1.84 \pm 0.3$ * & $7.90 \pm 0.2^{* *}$ & $3.0 \pm 0.1$ * & $4.71 \pm 0.1$ * & $4.31 \pm 0.2$ * & $9.46 \pm 0.2$ * & $3.00 \pm 0.2$ & $4 . .71 \pm 0.1$ \\
\hline $\begin{array}{l}\text { Tibialis nticus } \\
\text { (Long tibila) }\end{array}$ & $.72 \pm 0.3^{* *}$ & $9.24 \pm 0.1^{* *}$ & $2.11 \pm 0.2^{* *}$ & $5.33 \pm 0.2$ ** & $3.63 \pm 0.2$ * & $8.76 \pm 0.1^{\star \star}$ & $1.00 \pm 0.1^{* *}$ & $3.0 \pm 0.2$ ** \\
\hline $\begin{array}{c}\text { Gluteus max. } \\
\text { (big antomatism) }\end{array}$ & $1.55_{ \pm} 0.2 *$ & $6.44 \pm 0.2^{* *}$ & $1.0 \pm 0.2^{* *}$ & $5.38 \pm 0.1$ ** & $3.50 \pm 0.1$ ** & $8.5 \pm 0.1--$ & $4.00 \pm 0.1^{* *}$ & $5.13 \pm 0.1--$ \\
\hline
\end{tabular}

$* *=$ Highly significant $(\mathrm{P}<0.01) \quad, *=$ Significant $(\mathrm{P}<0.05) \quad, \quad--=$ Non significant

$\mathrm{P}=$ Significancy level in comparison with before and after using of mobile phone. 
Table (3) : Effect of GMS exposure on EMG (response capacity) of human legs.

\begin{tabular}{|c|c|c|c|c|}
\hline \multirow{4}{*}{ Muscle Name } & \multicolumn{4}{|c|}{ Response capacity (mV) } \\
\hline & \multicolumn{2}{|c|}{ Right leg } & \multicolumn{2}{|c|}{ Left Leg } \\
\hline & Before & After & Before & After \\
\hline & $X \pm$ S.E. $P$ & $X \pm$ S.E P & $X \pm$ S.E. P & $X \pm$ S.E. $P$ \\
\hline $\begin{array}{l}\text { Four thigh bones } \\
\text { (Biges femoral) }\end{array}$ & $8.41 \pm 0.2$ * & $3.33 \pm 0.3^{* *}$ & $6.43 \pm 0.1^{* *}$ & $2.11 \pm 0.2^{* *}$ \\
\hline $\begin{array}{l}\text { Biceps long H } \\
\text { (Femoral thigh) }\end{array}$ & $9.5 \pm 0.1$ * & $4.5 \pm 0.1^{*}$ & $7.00 \pm 0.2$ * & $2.00 \pm 0.3$ * \\
\hline $\begin{array}{l}\text { Tibialis nticus } \\
\text { (Long tibila) }\end{array}$ & $9.33 \pm 0.2^{* *}$ & $4.48 \pm 0.2^{* *}$ & $6.89 \pm 0.2^{* *}$ & $2.21 \pm 0.2^{* *}$ \\
\hline $\begin{array}{c}\text { Gluteus max. } \\
\text { (Big antomatism) }\end{array}$ & $8.11 \pm 0.3^{* *}$ & $3.27 \pm 0.1^{* *}$ & $7.80 \pm 0.1^{* *}$ & $2.89 \pm 0.1$ ** \\
\hline
\end{tabular}

$* *=$ Highly significant $(\mathrm{P}<0.01), *=$ Significant $(\mathrm{P}<0.05), \quad--=$ Non significant

$\mathrm{P}=$ Significancy level in comparison with before and after using of mobile phone.

Table (4): Effect of GMS exposure on EMG (Amplitude and total activity) of human legs

\begin{tabular}{|c|c|c|c|c|c|c|c|c|}
\hline \multirow{4}{*}{$\begin{array}{c}\text { Muscle Name } \\
\text { Region }\end{array}$} & \multicolumn{4}{|c|}{ Amplitude(uV) } & \multicolumn{4}{|c|}{ Total activity (c/s) } \\
\hline & \multicolumn{2}{|c|}{ Right leg } & \multicolumn{2}{|c|}{ Left Leg } & \multicolumn{2}{|c|}{ Right leg } & \multicolumn{2}{|c|}{ Left Leg } \\
\hline & Before & After & Before & After & Before & After & Before & After \\
\hline & $X \pm$ S.E. P & $X_{ \pm}$S.E P & $X \pm$ S.E. P & $X \pm$ S.E. P & $X \pm$ S.E. P & $X_{ \pm}$S.E. P & $X \pm$ S.E. $P$ & $\mathrm{X} \pm$ S.E. $\mathrm{P}$ \\
\hline $\begin{array}{l}\text { Four thigh bones } \\
\text { (Biges femoral) }\end{array}$ & $5.27 \pm 0.1$ & $12.2 \pm 0.2^{* *}$ & $1.20 \pm 0.1^{* *}$ & $1.33 \pm 0.1^{\text {** }}$ & $5.13 \pm 0.1^{* *}$ & $\begin{array}{c}9.13 \pm 0.1- \\
-\end{array}$ & $3.23 \pm 0.2$ & $8.34 \pm 0.2$ \\
\hline $\begin{array}{c}\text { Biceps long H } \\
\text { (Femoral thigh) }\end{array}$ & $1.07 \pm 0.2$ * & $5.97 \pm 0.2^{* *}$ & $4.53 \pm 0.1^{* *}$ & $6.03 \pm 0.1^{*}$ & $4.44 \pm 0.1$ * & $7.95 \pm 0.2$ * & $2.50 \pm 0.2$ & $7.0 \pm 0.2$ * \\
\hline $\begin{array}{l}\text { Tibialis nticus } \\
\text { (Long tibila) }\end{array}$ & $1.53 \pm 0.1^{* *}$ & $5.57 \pm 0.2^{\star \star}$ & $5.33 \pm 0.2^{* *}$ & $8.07 \pm 0.2$ ** & $3.38 \pm 0.9$ * & $8.40 \pm 0.2^{* *}$ & $4.31 \pm 0.2$ ** & $8.82 \pm 0.1$ ** \\
\hline $\begin{array}{c}\text { Gluteus max. } \\
\text { (Big antomatism) }\end{array}$ & $6.03 \pm 0.3^{* *}$ & $11.0 \pm 0.1^{\star *}$ & $7.13 \pm 0.1$ ** & $7.80 \pm 0.1^{* *}$ & $2.9_{ \pm} 0.1^{* *}$ & $7.3 \pm 0.2-$ & $2.22 \pm 0.1$ ** & $6.95 \pm 0.2-$ \\
\hline
\end{tabular}

$* *=$ Highly significant $(\mathrm{P}<0.01) \quad, *=$ Significant $(\mathrm{P}<0.05) \quad, \quad--=$ Non significant

$\mathrm{P}=$ Significance level in comparison with before and after using of mobile phone.
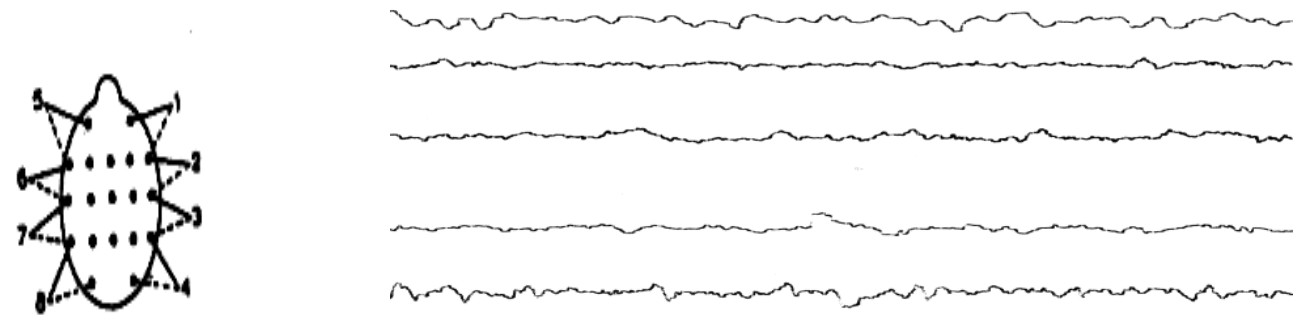

Figure (1): Normal EEG record showing a background activity formed of well organized alpha waves of 9-10 c/s. Man aged 23 years. 


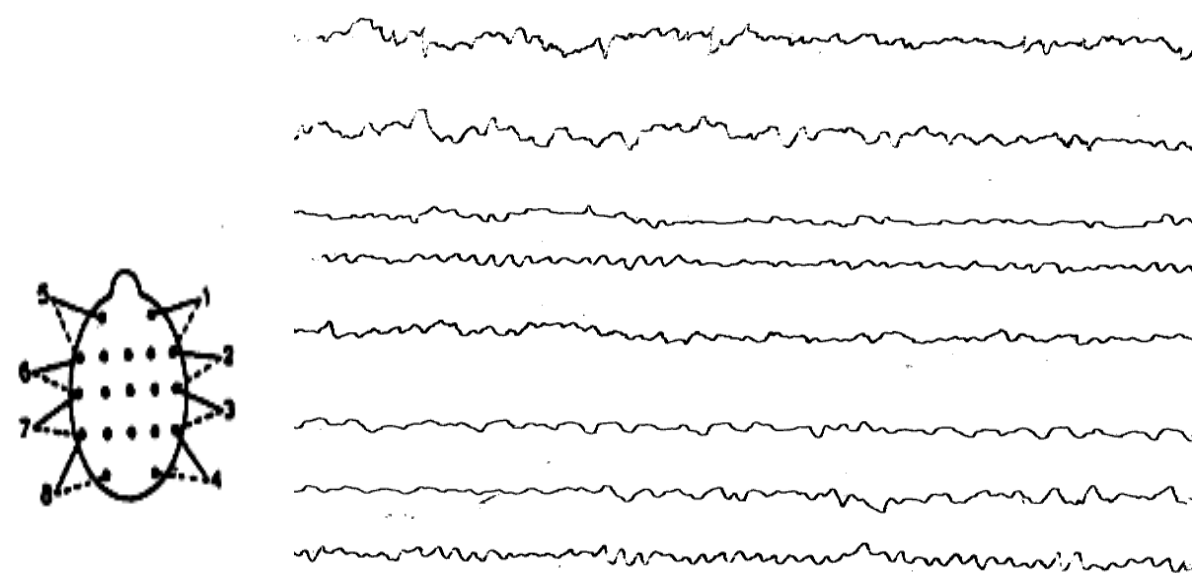

Figure (2 ): Normal EEG record showing a background activity formed of well organized alpha waves of 9-10 c/s. Man aged 25years.
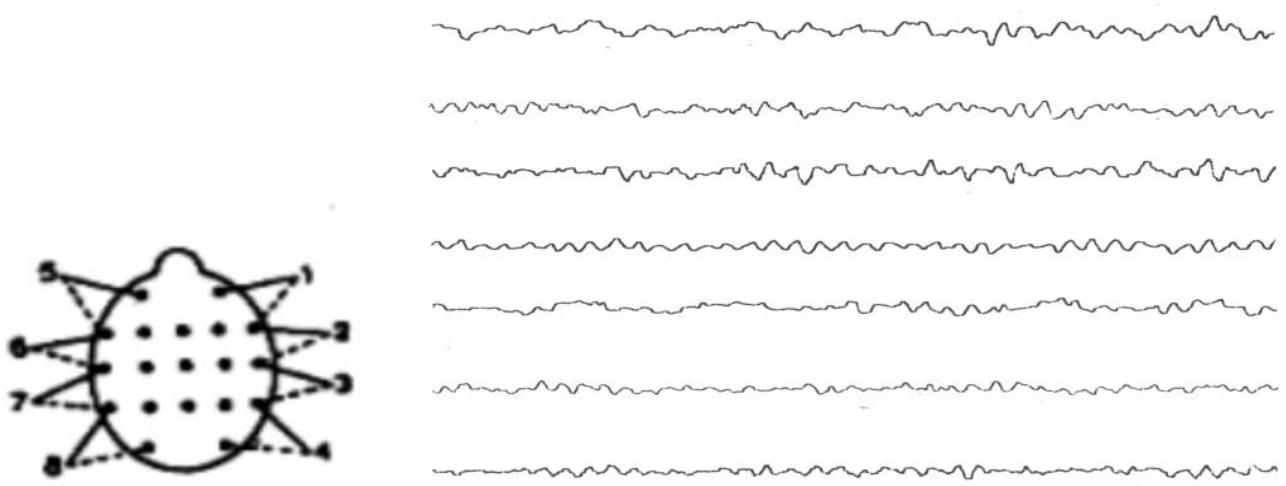

Figure (3): Normal EEG record showing a background activity formed of well organized alpha waves of $9-10 \mathrm{c} / \mathrm{s}$. Women aged 22 years.

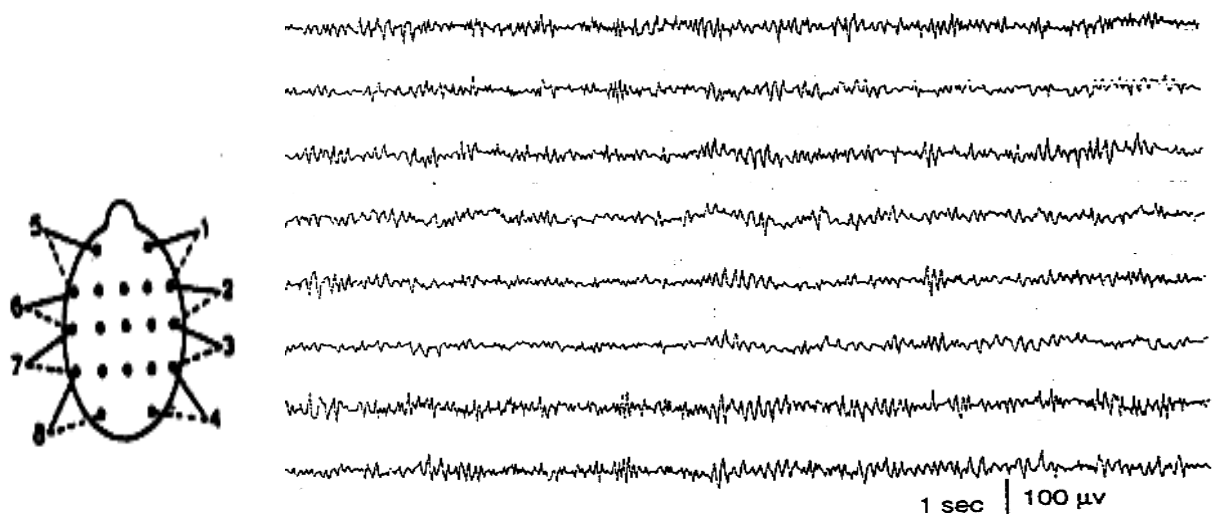

Figure (4): Excessive beta activity in man aged 25 years after two months of using the mobile phone. 


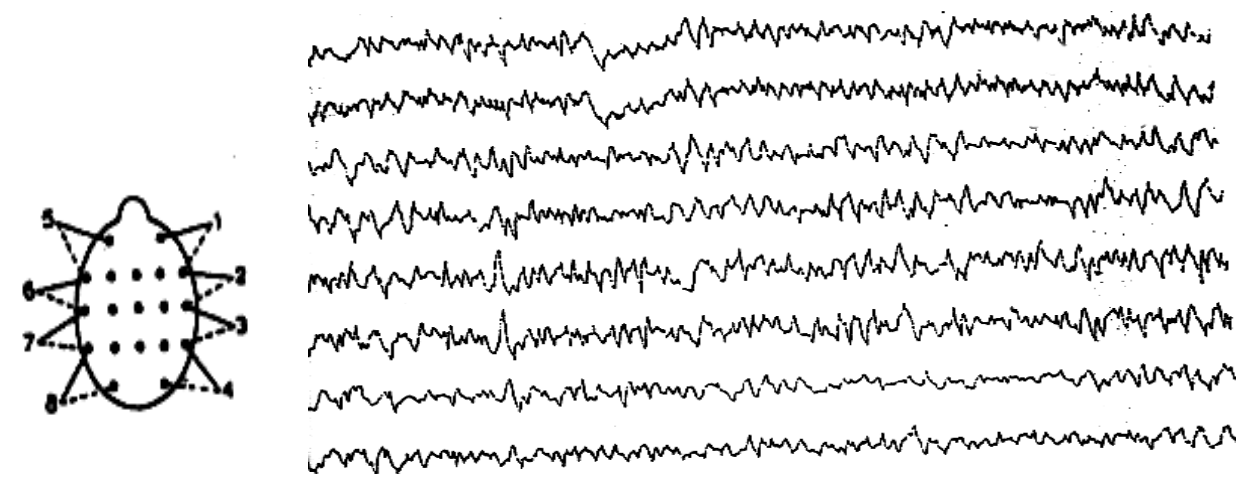

Figure (5): EEG showing fast and slow activity in man aged 23 years after two months of the using mobile phone.

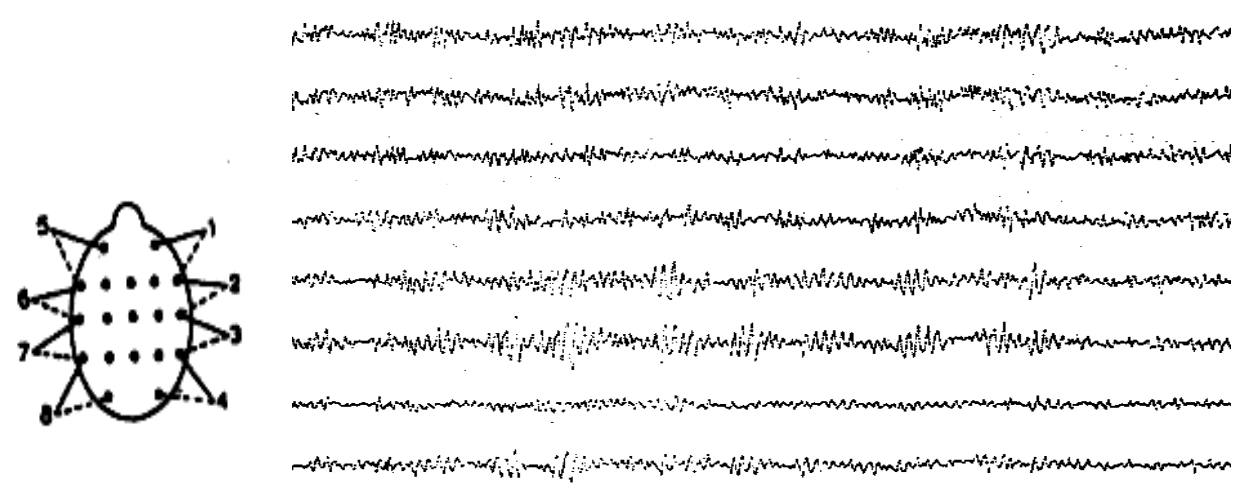

Figure (6): Excessive beta activity in women aged 22 years after two months of using a mobile phone.

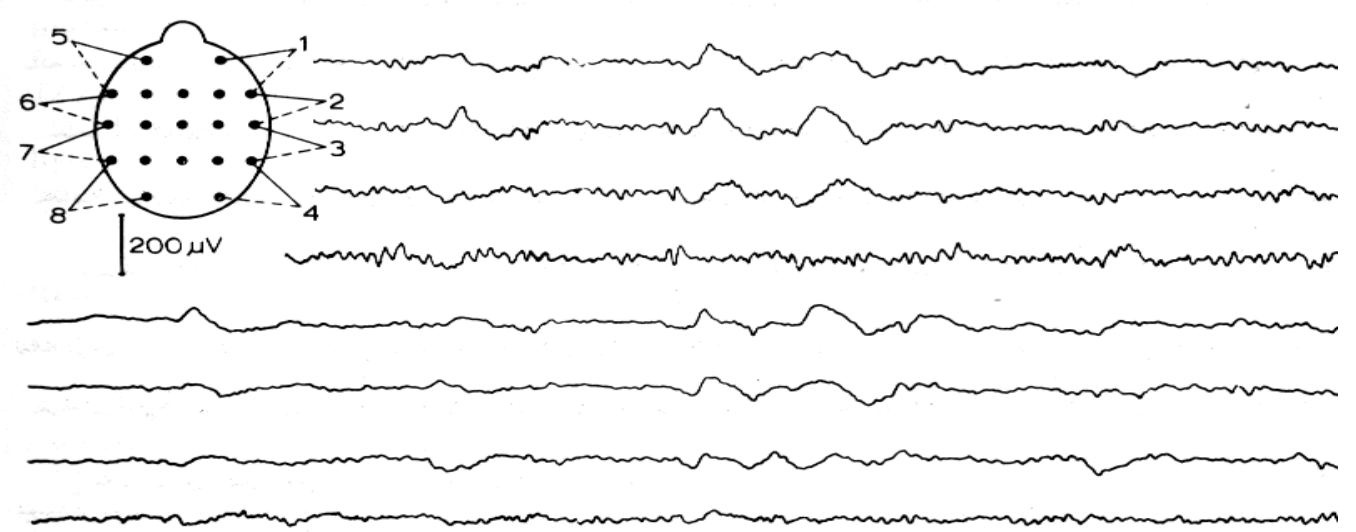

Figure ( 7 ): EEG of a women aged 20 years after one year from using a mobile phone, showing predominant delta activity of higher voltage (increasing drowsiness) . 


\section{Fathy El-Komey}

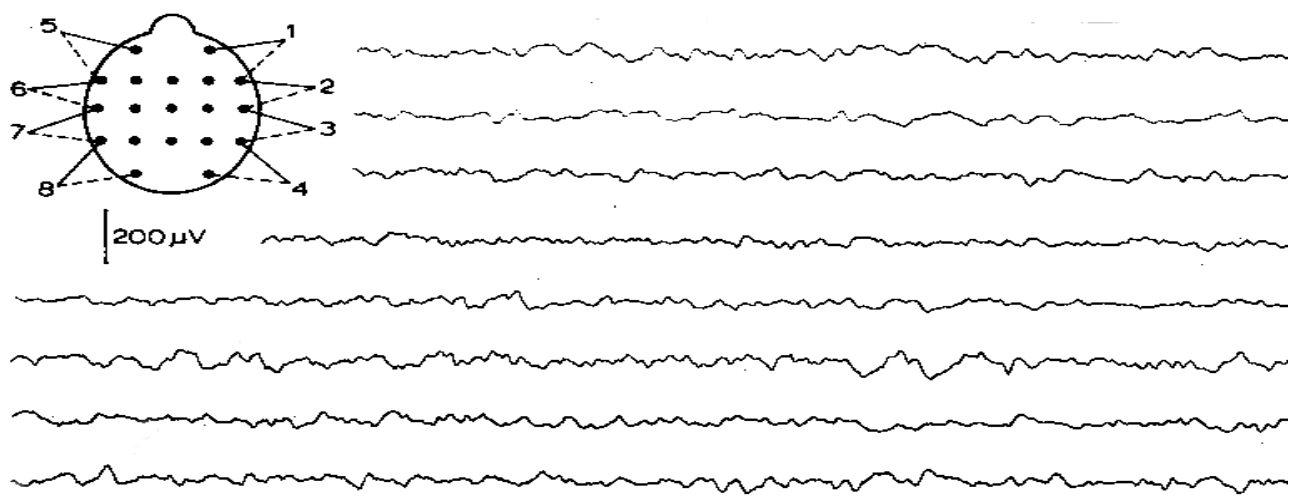

Figure ( 8 ): EEG of a women aged 22 years after one year from using a mobile phone, showing irregular delta activity of higher voltage (drowsiness)

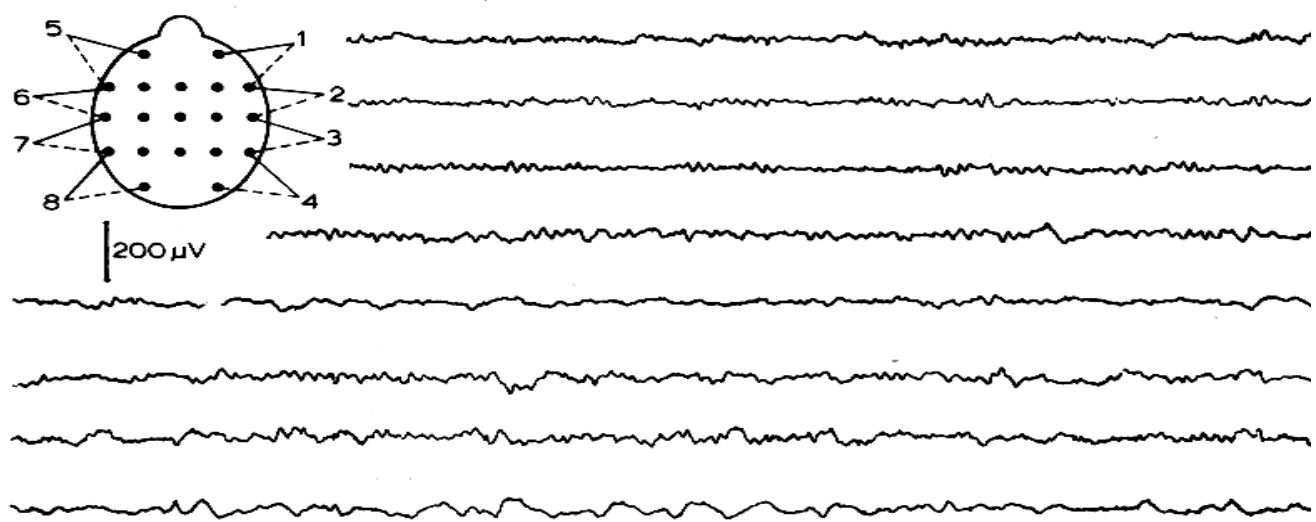

Figure (9 ) : EEG of a women aged 26 years after one year from using a mobile phone, showing widespread arrhythmic delta activity of higher voltage (slight dysphasia and drowsiness) .
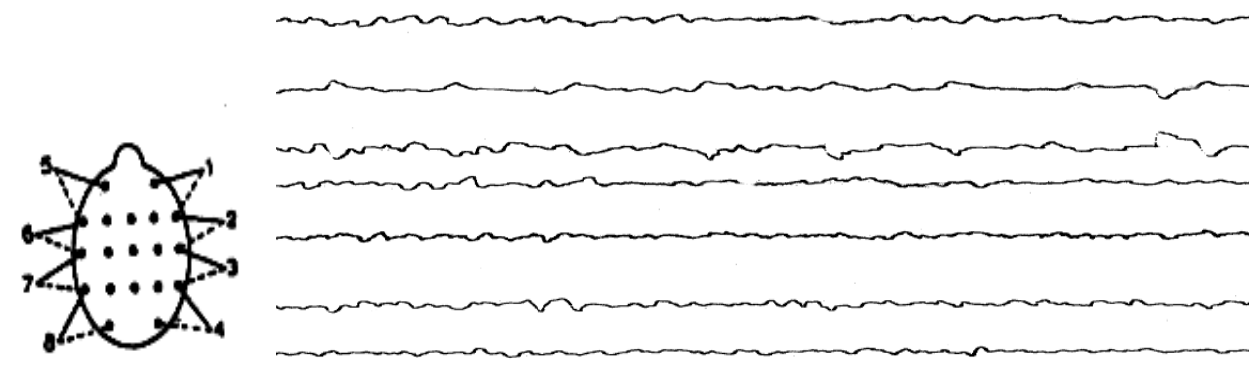

Figure (10): EEG record showing evidence of mild bitemporal focal cerebral dysrhythmia. Women aged 26 years after one year from using a mobile phone. 

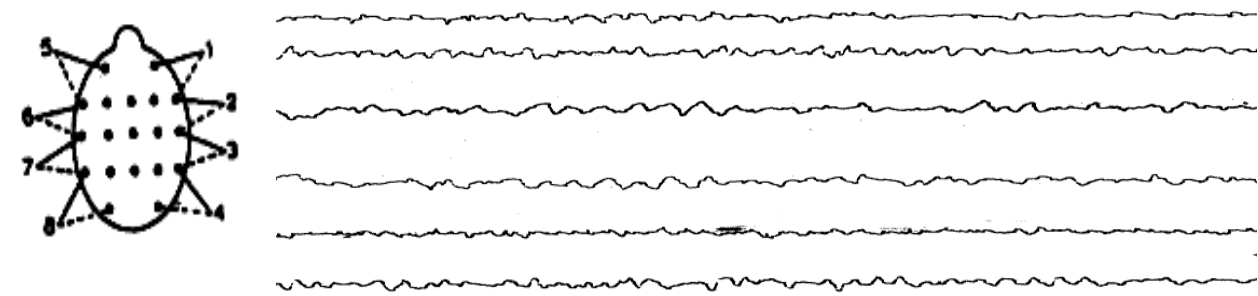

Figure (11): EEG record showing evidence of mild left temporal focal cerebral dysrhythmia .

Man aged 20 years after one year from using a mobile phone.

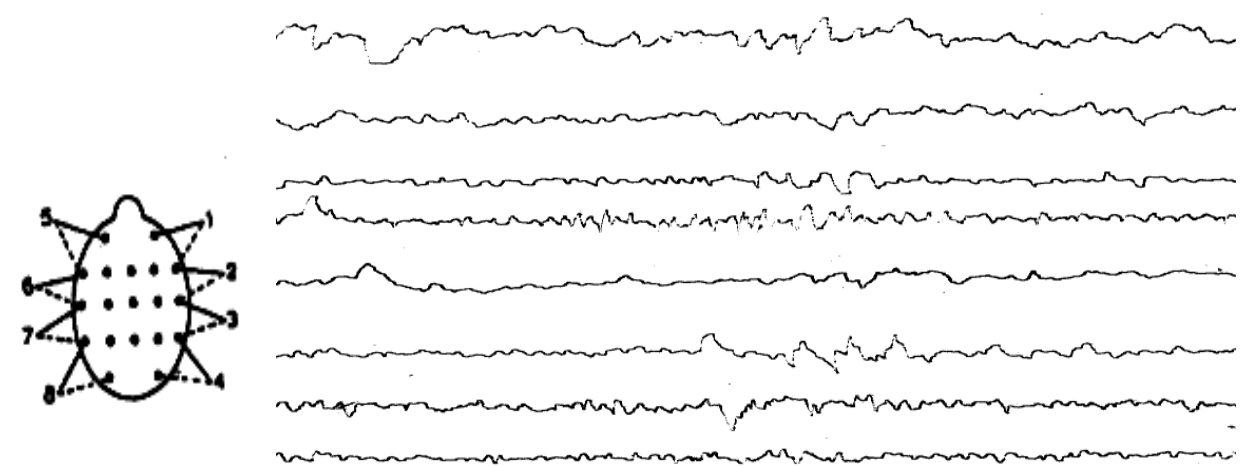

Figure (12): EEG record showing evidence of mild bitemporal focal epileptogenic dysfunction .Man aged 24 years after one year from using a mobile phone.
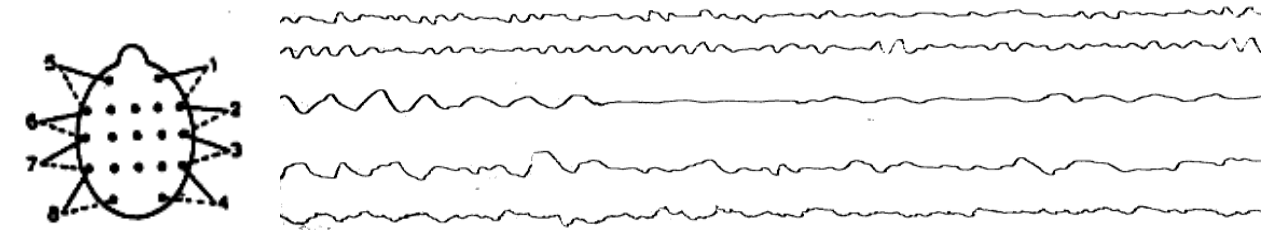

นח רm

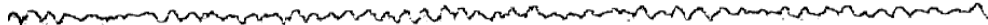

Figure (13): EEG record showing evidence of moderate left temporal focal cerebral dysrhythmia. Man aged 23 years after one year from using a mobile phone.
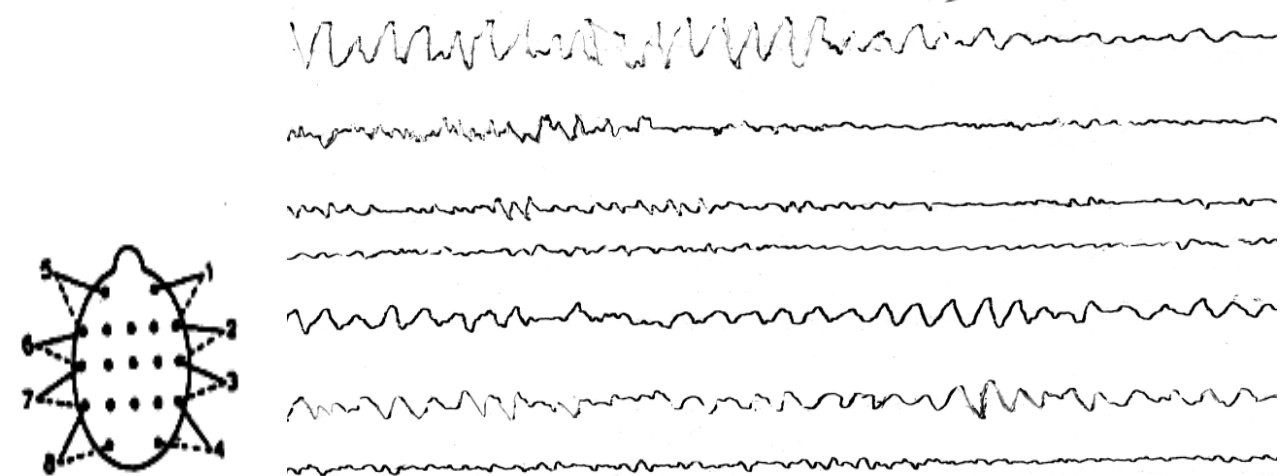

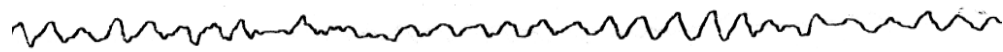

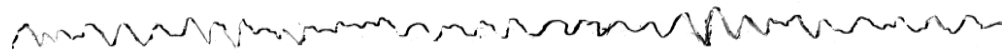

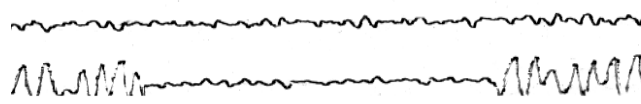

Figure (14): EEG record showing evidence of mild right temporal focal cerebral dysrhythmia. Man aged 25 years after one year from using a mobile phone. 


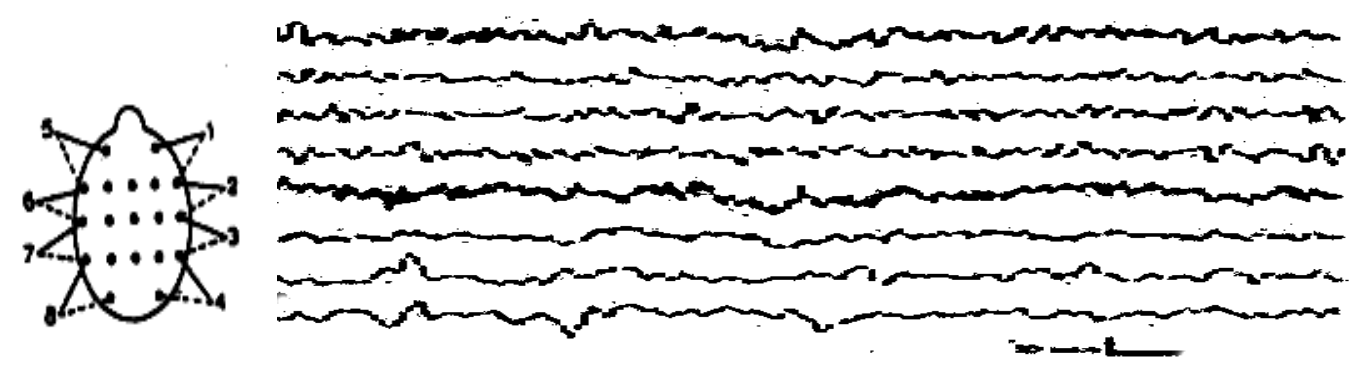

Figure (15): Focal EEG waveform abnormalities. Polymorphic delta activity. This EEG of a man aged 26 years- demonstrates polymorphic delta activity on the right, maximal in the parietal and occipital leads. This indicates an abnormality of white matter in that hemisphere. Also note the decrease in amplitude of the ongoing background activity on that side, indicating that an abnormality of cortical gray matter is present as well. The latter finding may be due to edema infiltration of the gray matter. Alternatively, it may be due to suppression of gray matter activity from disruption of axonal connections due to the underlying tumor, (this volunteer lived in last floor under station amplifier for GSM and after one year from using a mobile phone).

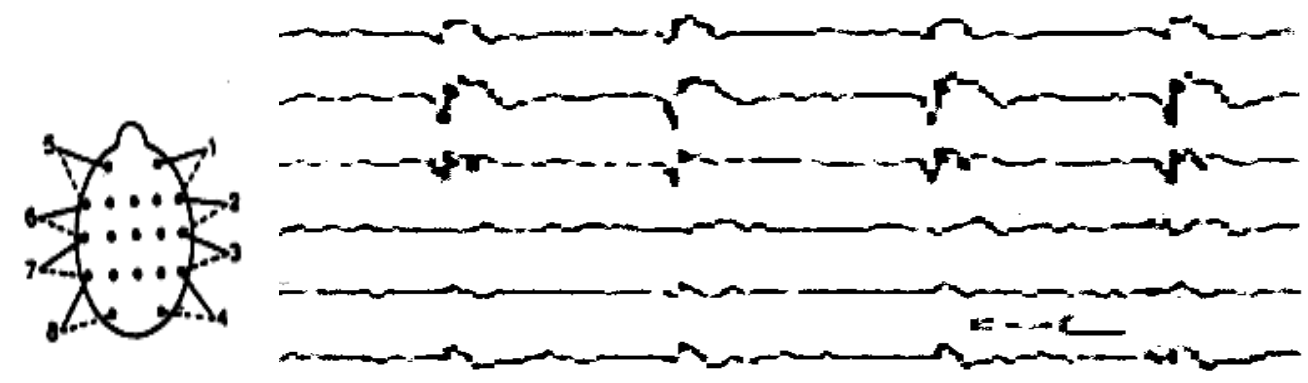

Figure (16): Focal EEG waveform abnormalities after one years from using a mobile phone. This EEG demonstrates periodic lateralized epileptiform discharges in the left hemisphere in a 24-years man, after one year from using a mobile phone.

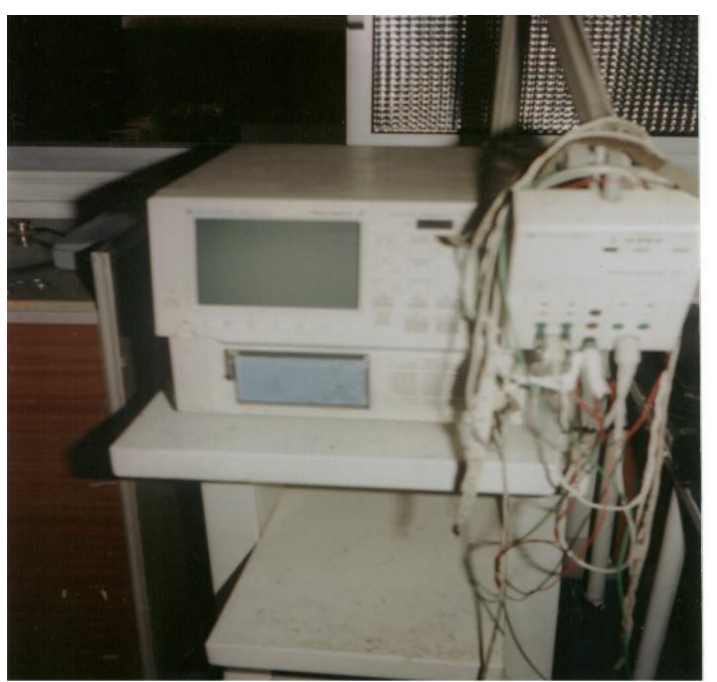

Figure(17): New Ropak's model 2 system two channels. 

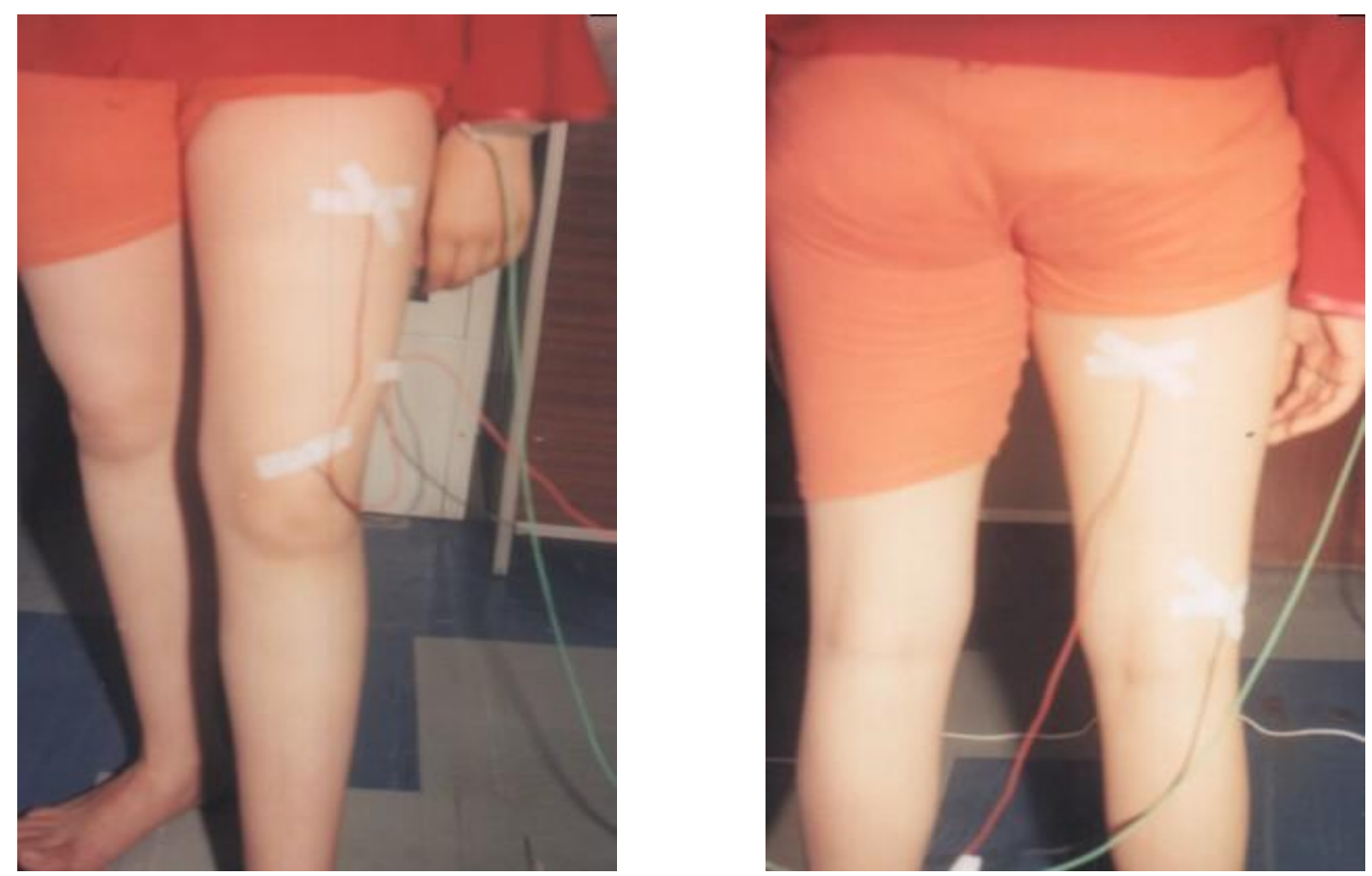

Figure(18):Example for positions electrode on muscle of leg

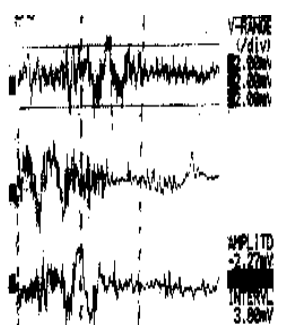

Right Four thigh bones (Biges femoral)

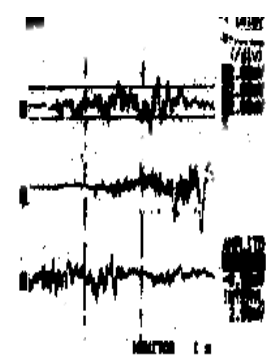

Gluteus max.

(Big antomatisn)

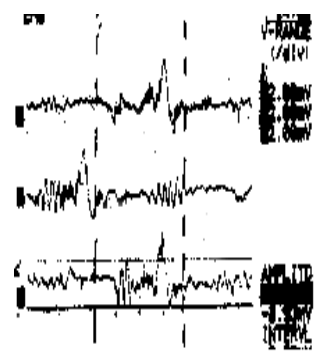

Tibialis nticus

(Long tibila)

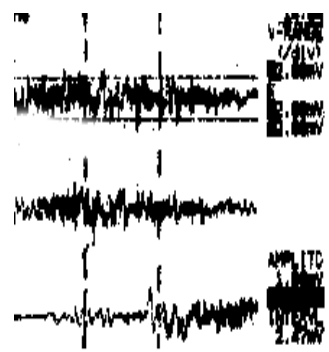

Biceps long $\mathbf{H}$

(Femoral thigh)

Figure (19): The raw EMG signals detected from four muscles from a subject right leg before using a mobile phone. The muscles are the Four thigh bones (Biges femoral), Gluteus max. (Big antomatisn), Tibialis nticus (Long tibila) and Biceps long $\mathrm{H}$ (Femoral thigh). 


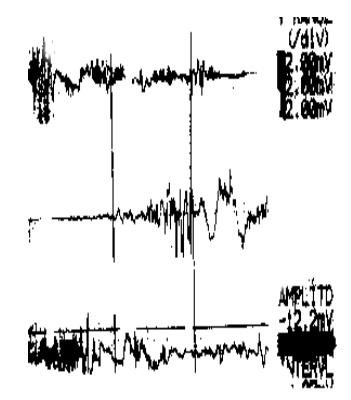

Right Four thigh bones

(Biges femoral)
Gluteus max.

(Big antomatisn)

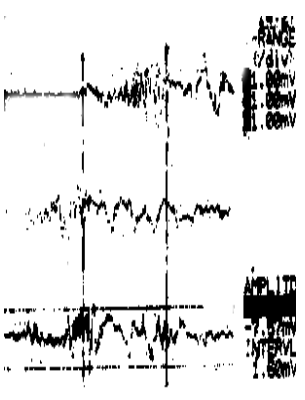

Tibialis nticus

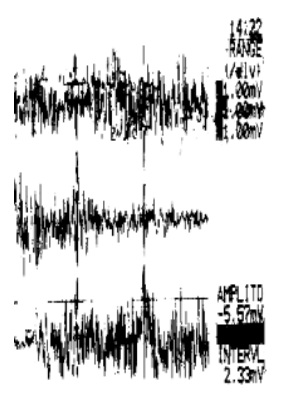

(Long tibila)

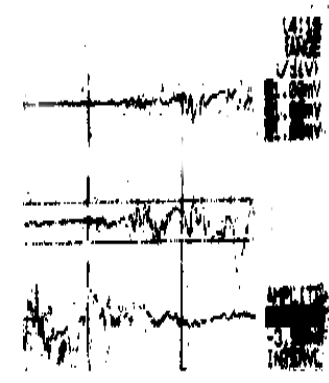

Biceps long $\mathbf{H}$

(Femoral thigh)

Figure (20): The raw EMG signals detected from four muscles from a subject right leg after using a mobile phone radiation emissions (for one year). The muscles are the Four thigh bones (Biges femoral), Gluteus max. (Big antomatisn), Tibialis nticus (Long tibila) and Biceps long $\mathrm{H}$ (Femoral thigh).

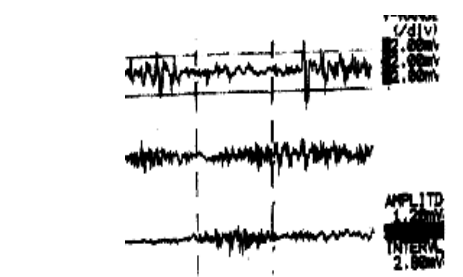

Left Four thigh bones

(Biges femoral)

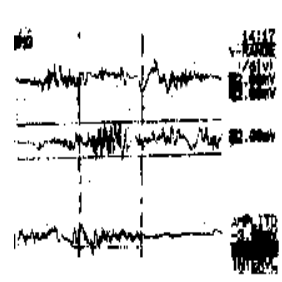

Gluteus max.

(Big antomatisn)

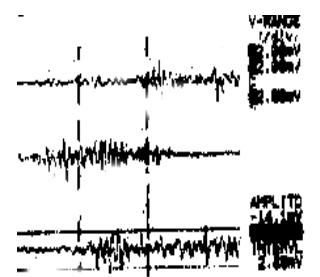

Tibialis nticus

(Long tibila)

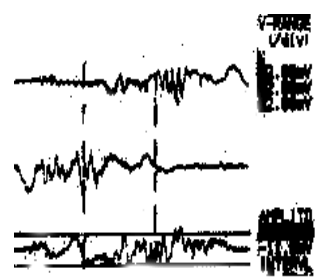

Biceps long $\mathbf{H}$

(Femoral thigh)

Figure (21): The raw EMG signals detected from four muscles from a subject left leg before using a mobile phone. The muscles are the Four thigh bones (Biges femoral), Gluteus max. (Big antomatisn), Tibialis nticus (Long tibila) and Biceps long $\mathrm{H}$ (Femoral thigh).

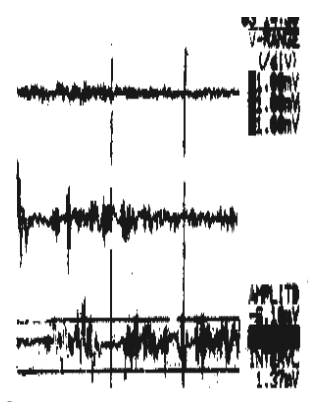

Left Four thigh bones

(Biges femoral)

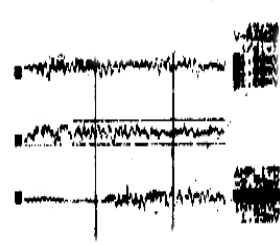

Gluteus max.

(Big antomatisn)

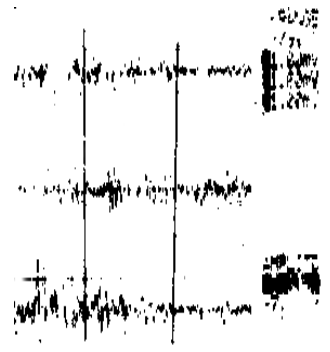

Tibialis nticus

(Long tibila)

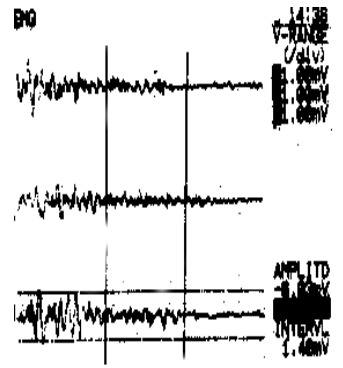

Biceps long $\mathbf{H}$

(Femoral thigh)

Figure (22): The raw EMG signals detected from four muscles from a subject leg after using a mobile phone radiation emissions (for one year). The muscles are the Four thigh bones (Biges femoral), Gluteus max. (Big antomatisn), Tibialis nticus (Long tibila) and Biceps long $\mathrm{H}$ (Femoral thigh). 


\section{References}

1- Adey, W.R. (1997): Bioeffects of communication fields; possible mechanisms of cumulative dose. In: Kuster, N., Balzano, Q. and Lin eds., Mobile Communication Safety, New York, Chapman and Hall. pp.103-139.

2- Ambrosio, G. R. and Massa et al. (2002): Cytogenetic damage in human lymphocytes following GMSK phase modulated microwave exposure. Bioelectromag 23:7-13.

3- Andrea, J.A. and E.R. Adair et al.(2003): Behavioral and cognitive effects of microwave exposure. Bioelectromag Supply, 6:S39-S62.

4- Andrea, J.A. and C.K. Chou et al.(2003): Microwave effects on the nervous system. Bioelectromag Supply, 6:S107-S147.

5- Barkhaus, P.E. and S.D. Nandedkar (1998): Electronic Myoanatomic Atlas for Clinical Electromyography (on CDROM). Hopewell Junction: CASA Engineering.

6- Barkhaus, P.E. and S.D. Nandedkar (1999): Electronic Atlas of Waveforms in Clinical Electromyography (on CDROM). Hopewell Junction: CASA Engineering.

7- Barkhaus , P.E. and S. D. Nandedkar (2003): EMG Evaluation of the Motor Unit: The Electrophysiological Biopsy. Emedicine Specialties; Neurology; Electromyography and Nerve Conduction Studies.1-13.

8- Basmajian, J. V. and R. Blumenstein (1983). Electrode placement in electromyographic biofeedback. In J. V. Basmajian (Ed.), Biofeedback: Principles \& practice for clinicians (pp. 363-378). Baltimore: Williams \& Wilkins.

9- Bonato, P.; T. D’Alessio and M. Knaflitz, (1998) :A statistical method for the measurement of muscle activation intervals from surface myoelectric signal during gait", IEEE Trans. Biomed. Eng., 45: 287-299.

10- Borbely, A.A., R. Huber, T.Graf and B. Fuchs et al. (1999): Pulsed high-frequency electromagnetic field affects human sleep and sleep encephalogram.Neuroscience Letters, 275: 207 - 210.

11- Burch, J.B.and J.S. Reif et al. (2002): Melaton in metabolite secretion among cellular telephone users. International Journal radiation Biology, 2; 78: 1029-1036.

12- Career Focus (2003): Clinical neurophysiology; 326: s183 (31 May), doi: 10. 1136/ bmj.326.7400.s183 BMJ Journals

13- Chia, S.E. and H.P. Chia et al. (2000): Prevalence of headache among handheld cellular telephone users in Singapore: A Community study. Environ Health Perspect, 108:1059-1062.

14- Costa, H.,G. Trueman ,L. Tang ,U. Abdel-rahman ,W. Abdel-rahman ,K. Ong , and I. Cosic (2003): Human brain wave activity during exposure to radiofrequency field emissions from mobile phones. Australa. Phys. Eng. Sci. Med., 26(4):162-167.

15- David, R., E.David and J.Reissenweber (1997): Effects of circularly polarized magnetic $50 \mathrm{~Hz}$ flux densities of 100 microtesla on night time melatonin serum levels in healthy volunteers. Second World Congress for Electricity and Magnetism in Biology and Medicine, 8-13 June, Bologna, Italy, Abstract No. J-1, p. 140.

16- Edelstyn, N. and A. Oldershaw (2002): The acute effects of exposure to the electromagnetic field emitted by mobile phones on human attention. NeuroReport, 13:119-121.

17- Elder, J.A. and C.K. Chou (2003): Auditory response to pulsed radiofrequency energy. Bioelectromag Supply, 6:S162S173.

18- Ernst, N., and Lopes Da Silva F (1999): Electroencephalography:Basic Principles, Clinical Applications and Related Fields. Williams \& Wilkins fourth Edition, 1154.

19- Erren, T.C. (1997): Epidemiologic studies of EMG and breast cancer risk: biologically bused overview. In: The melatonin hypothesis: breast cancer and the use of electric power. Columbus: Battelle Press.

20- Freude, G., P. Ullsperger, S. Eggert, and I. Ruppe (1998): Effects of microwaves emitted by cellular phones on human slow brain potentials. Bioelectromagnetics; 19:384 - 7 .

21- Freude, G., P. Ullsperger, S. Eggert, and I. Ruppe (2000): Microwaves emitted by cellular telephones affect human slow brain potentials. European Journal of Applied Physiology; 81:18 - 27.

22- Frey, A.H. (1998) Headaches from cellular telephone: Are they reap and what are the implications? Environmental Health Perspectives, 106, $101-103$.

23- Hamblin, D.L. and A.W. Wood (2002): Effects of mobile phone emissions on human brain activity and sleep variables. Int. J. Rad. Biol., 78:659-669.

24- Hamblin, D.L. and A.W. Wood et al. (2004): Examining the effects of 
electromagnetic fields emitted by GSM mobile phones on human event-related potentials and performance during an auditory task. Clin. Neurophys, 115:171178.

25- Hardell, L. and A. Hallquist et al. (2002): Cellular and cordless telephones and the risk for brain tumors. Eur. J. Cancer Prev., 11:377-386.

26- Hardell, L. and K.H. Mild et al. (2002): Case-control study of the use of cellular and cordless phones and the risk of malignant brain tumours. Int. J. Rad. Biol., 78:931-936.

27- Hardell, L. and K.H. Mild et al. (2003a): Further aspects on cellular and cordless telephones and brain tumours. Int. J. Oncol., 22:399-407.

28- Hardell, L. and K.H. Mild et al. (2003b): Vestibular schwannoma, tinnitus and cellular telephones. Neuroepidemiology, 22:124-129.

29- Hocking, B. and et al. (1996): Cancer incidence and mortality and proximity to TV towers. Med. J. Austral., 165:601-605.

30- Hossmann, K.A. and D.M. Hermann (2003): Effects of electromagnetic radiation of mobile phones on the central nervous system. Bioelectromag, 24:49-62.

31- Huber, R.,T. Graf, K.A.Cote and L. Wittman, et al. (2000): Exposure to pulsed high-frequency electromagnetic field during waking affects human sleep EEG. NeuroReport; 11:3321-3325.

32- Huber, R., V.Troyer,A.A. Borbely and J.Schuderer ,et al.(2002): Electromagnetic fields, such as those from mobile phones, alter regional cerebral blood flow and sleep and waking EEG. J. Sleep Res.;11:280-295.

33- Huber, R. and J. Schuderer, et al (2003): Radio frequency electromagnetic field exposure in humans: Estimation of SAR distribution in the brain, effects on sleep and heart rate. Bioelectromag, 24:262-276.

34- Jech, R.,K. Sonka ,E. Ruzicka and Nebuzelsky, et al. (2001):Electromagnetic field of mobile phone affects visual event related potential in patients with narcolepsy. Bioelectromagnetics; 22:519-528.

35- Johansen, C. and J.D. Boice, et al. (2001): Cellular telephones and cancer -- a nationwide cohort study in Denmark. J. Natl. Cancer Inst., 93:203-207.

36- Johen, L-Andreassi (2000): Psychophysiology human behavior and physiological response: Muscle Activity and Behavior. Fourth Edition, Lawrence Erlbaum
Associates, Publishers Mahwah, New Jersey-London. Chapter 8:164-190.

37- Kramarenko, A.V. and U. Tan (2003): Effects of high-frequency electromagnetic fields on human EEG: a brain mapping study. Int J Neurosci, 113:1007-1019.

38- Krause, C.M., L.Sillanmäki , M.Koivisto ,A. Häggqvist, et al. (2000): Effects of electromagnetic field emitted by cellular phones on the EEG during a memory task. NeuroReport; 11:761-764.

39- Krause, C.M., L. Sillanmaki ,M. Koivisto and A. Haggquist, et al. (2000): Effects of electromagnetic fields emitted by cellular phones on the electroencephalogram during a visual working memory task. International Journal of Radiation Biology; 76:1659-1667.

40- Krause, C.M. and C. Haarala, et al. (2004): Effects of electromagnetic field emitted by cellular phones on the EEG during an auditory memory task: A double blind replication study. Bioelectromag, 25:33-40.

41- Kuster, N.,Q. Balzano and J.Lin , Eds (1997): Mobile Communication Safety. New York, Chapman and Hall.p. 279.

42- Lee, T.M.C. and P.K. Lam, et al. (2003): The effect of the duration of exposure to the electromagnetic field emitted by mobile phones on human attention. Neuro.Report., 14:1361-1364.

43- Lippold, O. C. J. (1967): Electromyography. In P. H. Venables \& I. Martin (Eds.), Manual of psycho-physiological methods (pp. 245-297). Amsterdam; NorthHolland.

44- Lopes da Silva, F. (1982): EEG analysis: theory and practice. In Electroencephalography, Basic Principles, Clinical Applications and Related Fields Edited by Neidermyer E, Lopes da Silva F. Baltimore/ Munich. Urban and Schwartzenberg; 685711.

45- Marino, A.A., E.Nilsen and C.Frilot (2003): Nonlinear changes in brain electrical activity due to cell phone radiation. Bioelectromagnetics, 24(5):339-346.

46- Mashevich, M. and D. Folkman, et al. (2003): Exposure of human peripheral blood lymphocytes to electromagnetic fields associated with cellular phones leads to chromosomal instability. Bioelectromag, 24:82-90.

47- Merletti, R. and R.L.Lo Conte (1995): Advances in processing of surface myoelectric signals - Part 1.Medical \& 
Biological Engineering \& Computing, 5:361-372.

48- Mild, K.H. ,G.Oftedal ,M. Sandstrom ,J. Wilen ,T. Tynes ,B. Haugsdal and E. Hauger ( 1998): Comparison of symptoms experienced by users of analogue and digital mobile phones. A SwedishNorwegian epidemiological study. National Institute for Working Life, 23. Umea, Sweden.

49- Muscat, J.E. and M.G. Malkin, et al (2000): Handheld cellular telephone use and risk of brain cancer. JAMA 284:30013007.

50- Nandedkar, S.D. and P.E.Barkhaus (2001): Quantitative EMG analysis. In: Katirji B, Kaminski HJ, Preston DC, et al, eds. Neuromuscular Disorders in Clinical Practice. Boston: Butterworth-Heinemann.

51- Nandedkar, S.D. and P.E. Barkhaus (2002): Quantitative analysis: Objective and interactive assessment of the EMG signals. In: Bertorini T, ed. Evaluation and Diagnostic Tests in Neuromuscular Disorders.Boston:Butterworth Heinnemann.

52- Oftedal, G. and J. Wilén, et al. (2000): Symptoms experienced in connection with mobile phone use. Occupy Med., 50:237245.

53- Pfurtscheller, G. and F.H. Lopes da Silva (1999): Event-related EEG/MEG synchronization and desynchronization: Basic principles.Clin Neurophysiology, 110: 1842- 1857.

54- Reiser, H., W.Dimpfel , and F. Schober (1995): The influence of electromagnetic fields on human brain activity. European Journal of Medical Research; 16:27-32.

55- Salford, l. and et al. (2003): Nerve damage in mammalian brain after exposure to micro waves from GMS mobile phones. Journal National Institute of ENVIRONMENTAL Health Available 'on-line', 29 January.
56- Smith, C.W. and S. Best (1989): Electro magnetic Man" J.M. Dent and Sons Ltd, London (ISBN: 0-460-04698-5)

57- Stang, A. (2001): The possible role of radio -frequency radiation in the development of uveal melanoma. Epidemiology, 12(1), 7-12.

58- Stang, A. and G. Anastassiou, et al (2001): The possible role of radiofrequency radiation in the development of uveal melanoma. Epidemiology, 12:7-12.

59- Tahvanainen, $K$. and J. Niño, et al (2004): Cellular phone use does not acutely affect blood pressure or heart rate in humans. Bioelectromag., 25:73-83.

60- Tice, R.R. and G.G. Hook, et al. (2002): Genotoxicity of radiofrequency signals. I. Investigation of DNA damage and micronuclei induction in cultured human blood cells. Bioelectromag., 23:113-126.

61- Thompson, R. F., D.B. Lindsley and R.G. Eason (1966): Physiological psychology. New York: McGraw-Hill. Travis, R. C., \& Kennedy, J. L. (1949). Prediction and control of alertness. III. Calibration of the alertness indicator and further results. Journal of Comparative \& Physiological Psychology, 40, 457-461.

62- -Trosic, I. and I. Busljeta, et al. (2002): Micronucleus induction after whole-body microwave irradiation of rats. Mutat Res 521:73-79.

63- Winter, D. A.( 1990): Biomechanics and motor control of human movement, 2nd edn. Wiley Inter-science, New York

64- Zwamborn, A.P.M. and S.H.A.H. Vossen , et al. (2003): Effects of Global Communication system radio-frequency fields on Well Being and Cognitive Function of human subjects with and without subjective complaints (Report FEL-03-C148). The Hague, the Netherlands, Netherlands Organ-ization for Applied Scientific Research (TNO). 


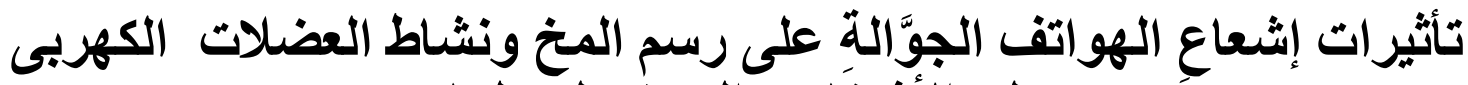

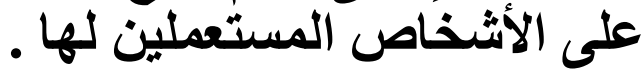

$$
\text { المركز القومى للبحوث قتاوى الاجتماعية والجنائية }
$$

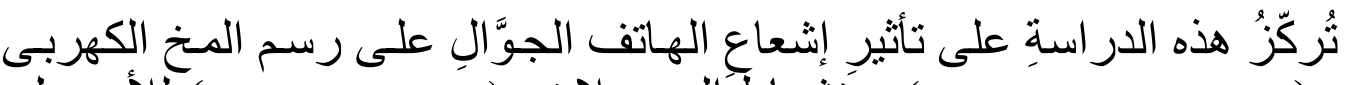

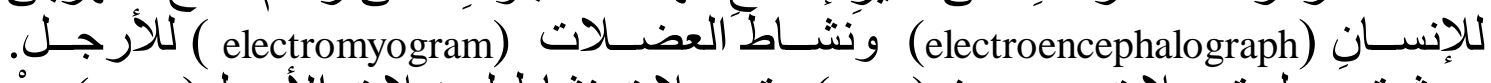

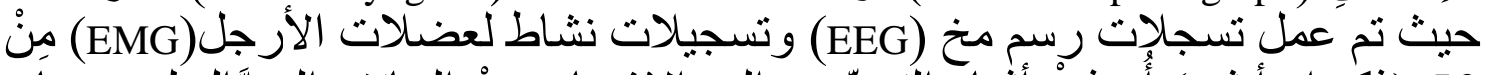

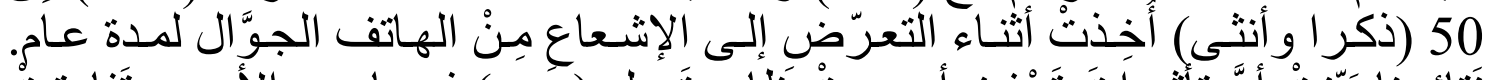

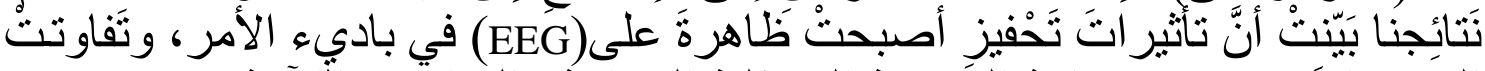

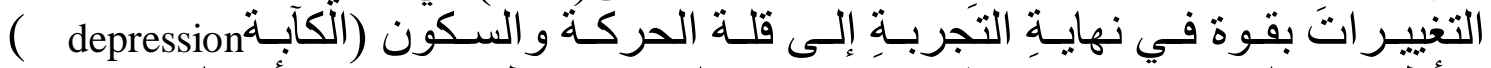

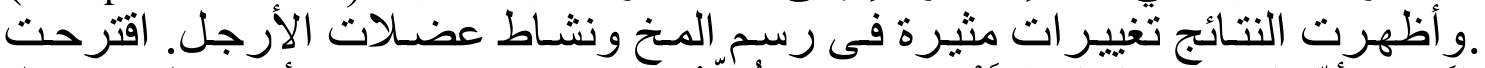

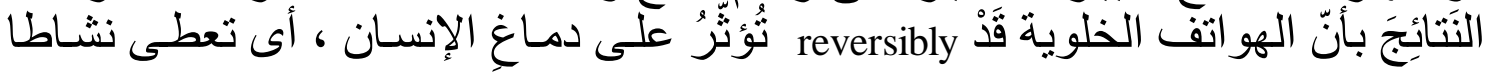

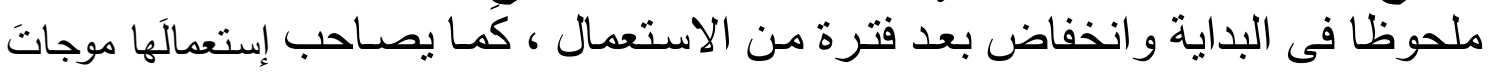
بطيئة شاذّةَ في رسم المخ للأشخاصِِ المستيقظينِ بعد عام من الاستخدام. 